\title{
PHOTOCATALYTIC OXIDATION OF TCE AND MTBE IN THE GAS PHASE
}

\author{
O. KATSANOU ${ }^{1, *}$ \\ E. ZERVAS ${ }^{2}$ \\ S.G. POULOPOULOS ${ }^{1}$ \\ C.J. PHILIPPOPOULOS ${ }^{1}$
}

Received: 20/06/07

Accepted: 04/10/07

\author{
${ }^{1}$ National Technical University of Athens, Greece, \\ 9 Heroon Polytechniou Str., Zografou Campus, \\ 15780 Athens Greece \\ ${ }^{2}$ Ecole des Mines de Nantes, DSEE, France \\ Present address: Democritus University of Thrace
}

*to whom all correspondence should be addressed: e-mail: h99008@mail.ntua.gr

\begin{abstract}
Photocatalysis is a promising method for eliminating the volatile organic compounds emitted from various industrial processes because mild or ambient conditions are used. Titanium dioxide is commonly used as photocatalyst and ultraviolet light is utilized for decomposing gas phase pollutants. In the present work, the photocatalytic oxidation of methyl tert butyl ether (MTBE) and trichloroethylene (TCE) in the gas phase was studied. The impact of residence time, TCE/MTBE concentration and oxygen concentration on TCE/MTBE conversion and byproduct formation was examined. Acetone and tert-butyl formate were detected at the reactor outlet from MTBE decomposition, whereas dichloroacetyl chloride (DCAC) and phosgene were found as by-products of TCE oxidation. The residence time affected dramatically both TCE and MTBE photo-oxidation as well as by-products existence and configuration. In contrast, the variation of oxygen inlet concentration affected significantly only MTBE conversion. Finally, the increase in MTBE and TCE inlet concentration had as a result decreased conversions observed.
\end{abstract}

KEYWORDS: photocatalysis, titanium dioxide, VOCs

\section{INTRODUCTION}

Large quantities of volatile organic compounds (VOCs) are released into the atmospheric environment day after day due to industrial and domestic activities. Moreover, atmosphere is also polluted in our effort to purify contaminated water using methods that transfer pollution from one phase to other such as air stripping. Beyond the fact that many VOCs are toxic or accused of causing respiratory problems or even cancer, they are also involved in photochemical reactions in the atmosphere forming tropospheric ozone (in the presence of NOx) or contributing to the depletion of stratospheric ozone layer. They may also be implicated in global warming.

Much attention has been given on photocatalytic oxidation for VOC elimination and this process seems to be very attractive because mild or ambient conditions are used. Photocatalysis has been extensively studied in the case of polluted wastewaters, but a rather small percentage of literature in connection with photocatalysis is devoted to the gas-phase (Hager et al., 2000; Hager et al., 1999, Khan et al., 2000; Mohseni et al., 2003; Wang et al., 1998a; Wang et al., 1998b).

Titanium dioxide in various forms is almost exclusively used as photo-catalyst. Various compounds have been used as model compounds in the gas-phase photo-oxidation, such as butanol, trichloroethylene, toluene, acetone, ethanol, diethyl ether, nitroglycerine, monoterpenes, acetaldehyde, benzene and heptane.

In the present work, the efficiency of the photocatalytic destruction of trichloroethylene (TCE) and methyl-tert-butyl ether (MTBE) in the gas-phase using UV light and titanium dioxide was studied. $\mathrm{TiO}_{2}$ was coated on the inner side of the photoreactor. Specifically, the effect of 
residence time, TCE/MTBE concentration and oxygen concentration on TCE/MTBE conversion and by-product formation was examined.

\section{EXPERIMENTAL DETAILS}

Apparatus and Procedure. All experiments were conducted under atmospheric pressure in a tubular photoreactor. UV-light of $253.7 \mathrm{~nm}$ was provided by a low pressure $18 \mathrm{~W} \mathrm{Hg}$ lamp. $\mathrm{TiO}_{2}$ was coated on the inner side of the photoreactor using the isopropoxide method. MTBE or TCE was introduced into the reactor by bubbling a stream of helium through an MTBE or TCE saturator. The saturator was thermostated at $-25^{\circ} \mathrm{C}$ for MTBE or at $-1^{\circ} \mathrm{C}$ in the case of TCE. Samples were taken for analysis from reactor inlet and outlet via a gas syringe.

Analysis. The reactor feed and product gases were analyzed via gas chromatography mass spectrometry (HP GC 6890 - MSD 5973). The column used was the HP5-MS (HP $190915-433), 30 \mathrm{~m}$ length, operated in the range of $40-220^{\circ} \mathrm{C}$. Helium was used as carrier gas. Acetone and tert-butyl formate (TBF) were found in MTBE product gases and dichloroacetyl chloride (DCAC), phosgene $\left(\mathrm{COCl}_{2}\right)$ in TCE product gases.

\section{EXPERIMENTAL RESULTS}

\section{MTBE}

Firstly, the effect of MTBE residence time on MTBE conversion was studied. The inlet concentration of MTBE and oxygen were 3000 and 5000 ppm, respectively. As it is obvious in Figure 1, MTBE conversion was dramatically affected by residence time variation in the range of $0,1-2 \mathrm{~min}$. $100 \%$ conversions were observed for residence time higher than $3 \mathrm{~min}$. Acetone was produced for residence time up to $1 \mathrm{~min}$.

Increasing the oxygen inlet concentration above $8000 \mathrm{ppm}$ leaded to decreased MTBE conversions due to less available active sites on catalyst for MTBE. Acetone was detected in the reactor effluent in all cases, whereas TBF was found in the cases of MTBE partial oxidation.

The increase in MTBE inlet concentration had also a negative effect on MTBE conversion (Figure 2). In contrast, TBF production was slightly changed by MTBE inlet concentration variation.

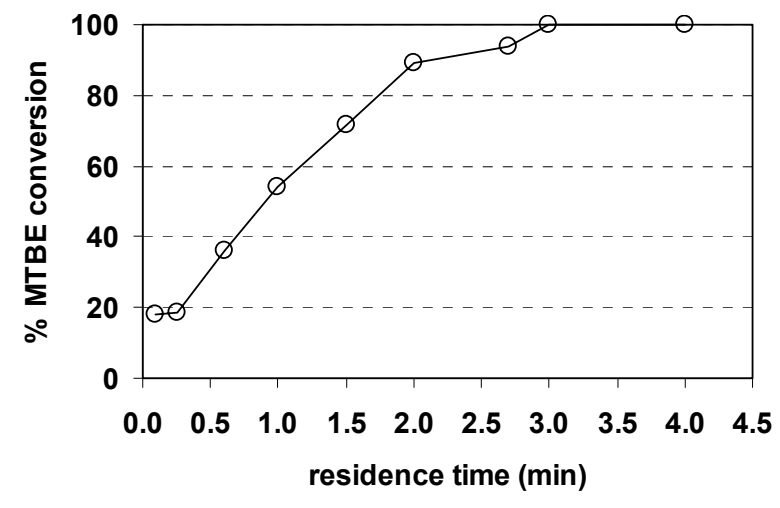

Figure 1. The effect of residence time on MTBE conversion

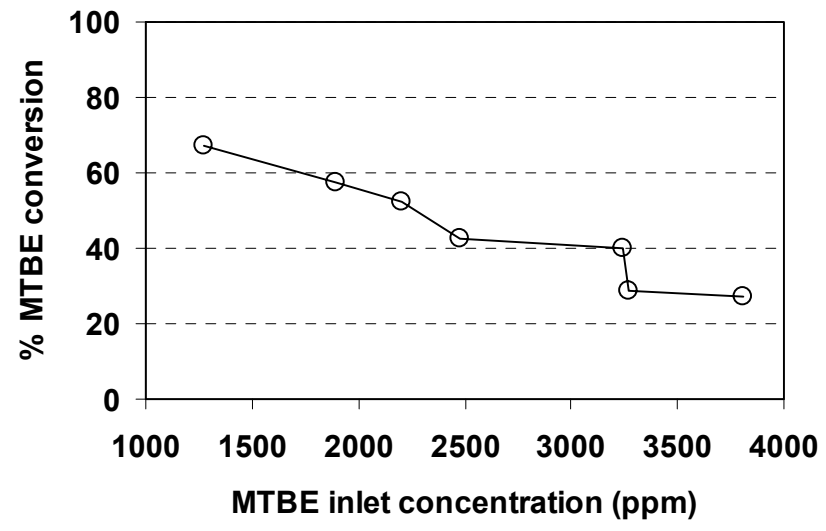

Figure 2. The effect of MTBE inlet concentration on MTBE conversion

\section{TCE}

The effect of residence time on TCE conversion was also studied. The inlet concentration of TCE and oxygen were 3900 and 5000 ppm, respectively. The conversion of trichloroethylene was dramatically enhanced with increasing the residence time in 6-29 sec, as shown in Figure 3. TCE conversion was rather stable in the range of 20-60 min. Phosgene was detected in the reactor effluent for residence time up to $30 \mathrm{sec}$, whereas DCAC was produced after $30 \mathrm{sec}$. 
In contrast to MTBE, the increase in oxygen inlet concentration had no effect on either trichloroethylene conversion or by-products formation.

In contrast, increasing the inlet concentration of trichloroethylene had as a result a gradual decrease in TCE conversion, as it is obvious in Figure 5, whereas the production of phosgene was enhanced (Figure 6).

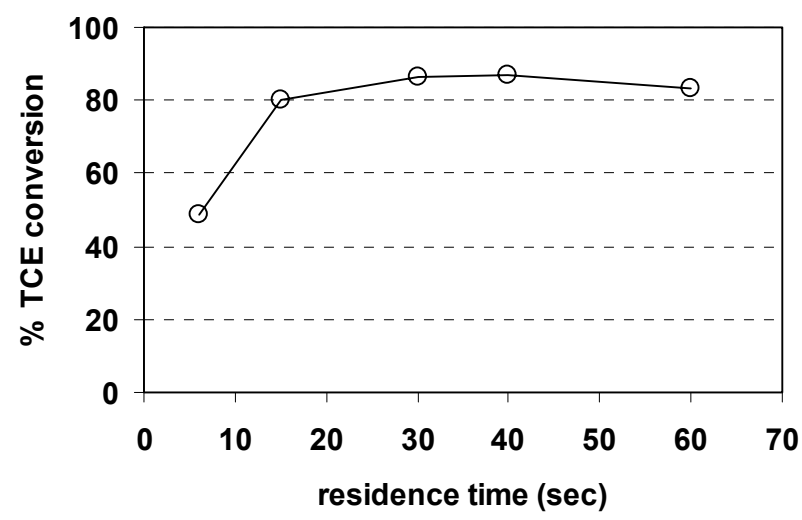

Figure 3. The effect of residence time on TCE conversion

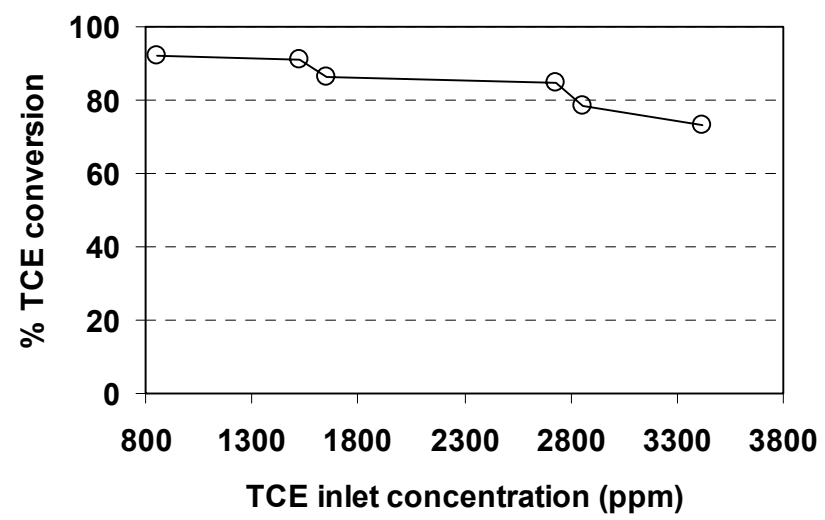

Figure 5. The effect of TCE inlet concentration on MTBE conversion

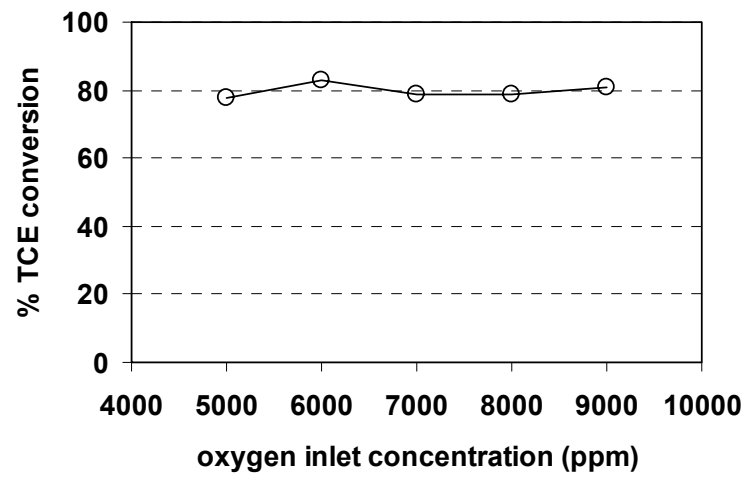

Figure 4. The effect of oxygen inlet concentration on TCE conversion

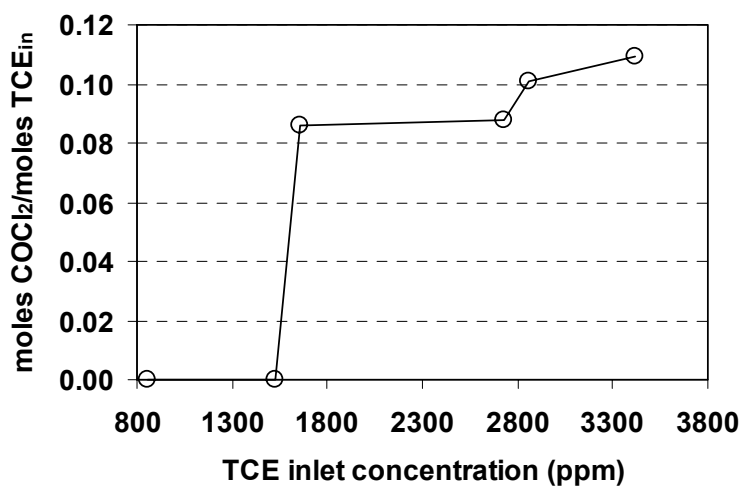

Figure 6. The effect of TCE inlet concentration on phosgene production

\section{CONCLUSIONS}

In the present study, the photocatalytic destruction of trichloroethylene and methyl-tert-butyl ether in the gas-phase using UV light and titanium dioxide was investigated. The effect of residence time, TCE/MTBE concentration and oxygen concentration on TCE/MTBE conversion and by-product formation was examined. Acetone and tert-butyl formate were detected in the photoreactor effluent as by-products of MTBE decomposition. The residence time had a significant effect on both TCE and MTBE photo-oxidation as well as by-products existence and configuration. In contrast, the variation of oxygen inlet concentration affected significantly only MTBE conversion. Finally, the increase in MTBE and TCE inlet concentration had as a result decreased conversions observed. 


\section{REFERENCES}

1. Hager S. and Bauer R., (1999), Heterogeneous photocatalytic oxidation of organics for air purification by near UV irradiated titanium dioxide, Chemosphere, 38(7), 1549-1559.

2. Hager S., Bauer R. and Kudielka G., (2000), Photocatalytic oxidation of gaseous chlorinated organics over titanium dioxide, Chemosphere, 41(8), 1219-1225.

3. Khan F. and Ghoshal A., (2000), Removal of Volatile Organic Compounds from polluted air, Journal of Loss Prevention in the Process Industries, 13(6), 527-545.

4. Mohseni M. and David A., (2003), Gas phase vinyl chloride (VC) oxidation using $\mathrm{TiO}_{2}$-based photocatalysis, Applied Catalysis B: Environmental, 46(2), 219-228.

5. Wang K., Tsai H. and Hsieh Y., (1998a), The kinetics of photocatalytic degradation of trichloroethylene in gas phase over $\mathrm{TiO}_{2}$ supported on glass bead, Applied Catalysis B: Environmental, 17(4), 313-320.

6. Wang K., Tsai H. and Hsieh Y., (1998b), A study of photocatalytic degradation of trichloroethylene in vapor phase on $\mathrm{TiO}_{2}$ photocatalyst, Chemosphere, 36(13), 2763-2773. 